\title{
Characteristic features of orthodontic treatment of tooth retention caused by hyperdontia
}

\section{Charakterystyka leczenia ortodontycznego zębów zatrzymanych z powodu ich nadliczbowości}

\author{
Valentyn Makeyev ${ }^{1, A, C, E, F}$, Nataliya Pylypiv², B-D, F, Volodymir Shybinskyy ${ }^{1, A, C, E, F}$ \\ 1 Department of Prosthodontics, Lviv National Medical University, Lviv, Ukraine \\ 2 Department of Orthodontics, Lviv National Medical University, Lviv, Ukraine \\ A - research concept and design; $\mathrm{B}$ - collection and/or assembly of data; $\mathrm{C}$ - data analysis and interpretation; \\ $D$ - writing the article; $E$ - critical revision of the article; $F$ - final approval of article
}

Address for correspondence

Valentyn Makeyew

E-mail: szybinski@ukr.net

Funding sources

none declared

Conflict of interest

none declared

Received on 0ctober 7, 2016

Revised on November 6, 2016

Accepted on December 4, 2016
DOI

$10.17219 / \mathrm{dmp} / 67514$

Copyright

(C) 2017 by Wroclaw Medical University

and Polish Dental Society

This is an article distributed under the terms of the

Creative Commons Attribution Non-Commercial License

(http://creativecommons.org/licenses/by-nc-nd/4.0/)

\begin{abstract}
Supernumerary teeth often cause tooth retention. The presence of supernumerary teeth, depending on their shape, number and location, can create unfavorable conditions for the development of the dental arches and occlusion, resulting in significant functional and esthetic disorders.

The article presents clinical cases of patients with hyperdontia and tooth retention. Each case involves a thorough patient examination and an individual approach to the choice of treatment. The authors' experience in treating retention caused by hyperdontia allowed a range of treatment methods to be used, depending on the functional state of occlusion, the patient's age and the characteristics and location of the impacted and supernumerary teeth. In two patients with dentition in the early transitional period, the central incisors erupted without a doctor's intervention within three months after the extraction of supernumerary teeth. In both cases, the subsequent orthodontic treatment aimed at correcting the torsiversion the incisors displayed upon eruption. Another case demonstrates a method of treatment that provides minimal loss of bone tissue: the supernumerary tooth were initially shifted to the alveolar bone surface and then removed. The last case describes a complete surgical-orthodontic treatment. Bone grafting was performed after the extraction of a supernumerary tooth, and an impacted tooth was moved to the newly created bone tissue. All these methods of treatment have their specific indications and can be implemented after a thorough examination of the patient.
\end{abstract}

Key words: hyperdontia, impacted teeth, tooth retention

Słowa kluczowe: nadliczbowość zębów, zęby zaklinowane, zatrzymanie zęba 
Tooth retention is an abnormality that requires attention for both scientific and practical reasons. Usually, this anomaly is accompanied by disturbances in the tooth eruption sequence, by tooth crowding, diastema and cyst formation. Among other causes, tooth retention is often caused by supernumerary teeth (ST), which occur as single, multiple, unilateral or bilateral anomalies in the maxilla, mandible or both jaws. ${ }^{1}$ A statistically significant association has been found between unerupted incisors and other inherited dental anomalies, in particular hyperdontia. ${ }^{2}$ The presence of supernumerary tooth is the most common cause of maxillary incisor eruption failure. Delayed eruption of associated teeth has been reported in $28-60 \%$ of Caucasians with supernumerary teeth. ${ }^{3}$

The clinical manifestations of hyperdontia can vary widely and depend on many factors: the number of supplemental teeth, their size, shape and location in the jaws. ${ }^{1,4}$ The presence of a supernumerary tooth or teeth often causes upper midline deviation, space loss, disturbed eruption or rotated central incisors. ${ }^{5,6}$ Supernumerary teeth located in the anterior region of the maxilla are usually palatally located. ${ }^{7}$

The location of supernumerary teeth plays a major role in the diagnosis and treatment, especially in determining the necessity of surgical intervention. ${ }^{8}$ The clinical diagnosis can be confirmed by radiographic examination. Anthonappa et al. reported that panoramic radiographs are not sufficient to reliably identify supernumerary teeth. ${ }^{9}$ Different radiographs are necessary to diagnose ST location. Widely used techniques for determining the location of supernumerary teeth include vertical tube shift and horizontal tube shift. In 2013, Toureno et al. proposed "a guideline to locate and identify supernumerary teeth in two and three dimensions, which may reduce treatment errors and improve communication among health care providers and third-party administrators". ${ }^{10}$

Surgical removal of impacted teeth requires great accuracy in the diagnosis and the localization of the teeth. Because of its 3D images, cone-beam computed tomography $(\mathrm{CBCT})$ has a greater potential than conventional radiography for providing precisely detailed information, so the possibility of surgical errors is greatly reduced. ${ }^{11,12}$

Each case of tooth retention, especially when caused by hyperdontia, requires an individual approach considering the patient's age and the location and topography of the teeth. ${ }^{13}$ This article presents some solutions to these issues.
Among 94 patients with tooth retention treated at the authors' departments, 24 cases were identified as involving retention of the upper central incisors. In 18 of these cases $(75.0 \%)$ the condition was caused by supernumerary teeth (Table 1).

The number of male patients with supernumerary teeth preventing the incisors from erupting was 3.5 times higher than the number of females. The primary therapeutic approach for patients with hyperdontia causing failure of incisor eruption is extraction of the supernumerary teeth.

In two patients with dentition in the early transitional period, after extraction of supernumerary teeth, the central incisors erupted within three months without a doctor's intervention. The orthodontic treatment that followed in both cases was aimed at correcting the torsiversion the incisors displayed upon eruption.

Below, examples of different clinical approaches to supernumerary tooth extraction are provided.

\section{Case reports}

\section{Case 1}

A nine-year-old girl was referred to the Department of Orthodontics of Lviv National Medical University (Lviv, Ukraine) with a lack of left central and lateral permanent incisors in the upper jaw. Clinical examination revealed the early period of primary occlusion, normognathic occlusion and a midline shift to the left; teeth 61 and 62 were present in the dental row. The intraoral radiograph and panoramic x-ray (Fig. 1) revealed retention of the left central and lateral incisors and supernumerary teeth that projected into the crowns of the retained teeth.

A CT scan was made to update and specify the location of the supernumerary teeth. To extract them, the decision was made to establish access to them through the opening that was made after extracting a deciduous incisor. The two supernumerary teeth were extracted (Fig. 2), and tooth 21 erupted independently after two months.

\section{Case 2}

A nine-year-old boy with a lack of central maxillary incisors was referred to the Department of Orthodontics. He was in the early period of primary occlusion. There were no visible lesions in the mucous membranes of the

Table 1. The distribution of patients and the location of the supernumerary teeth (selfobservation)

\begin{tabular}{|c|c|c|c|c|c|c|}
\hline \multirow{2}{*}{ Patient's sex } & \multicolumn{2}{|c|}{ Hyperdontia was an obstacle to eruption } & \multicolumn{2}{|c|}{ Hyperdontia wasn't an obstacle to eruption } & \multicolumn{2}{|c|}{ Total } \\
\hline & $n$ & $\%$ & $\mathrm{n}$ & $\%$ & $n$ & $\%$ \\
\hline Male & 14 & 58.3 & 2 & 8.3 & 16 & 66.6 \\
\hline Female & 4 & 16.7 & 4 & 16.7 & 8 & 33.4 \\
\hline Total & 18 & 75.0 & 6 & 25.0 & 24 & 100.0 \\
\hline
\end{tabular}




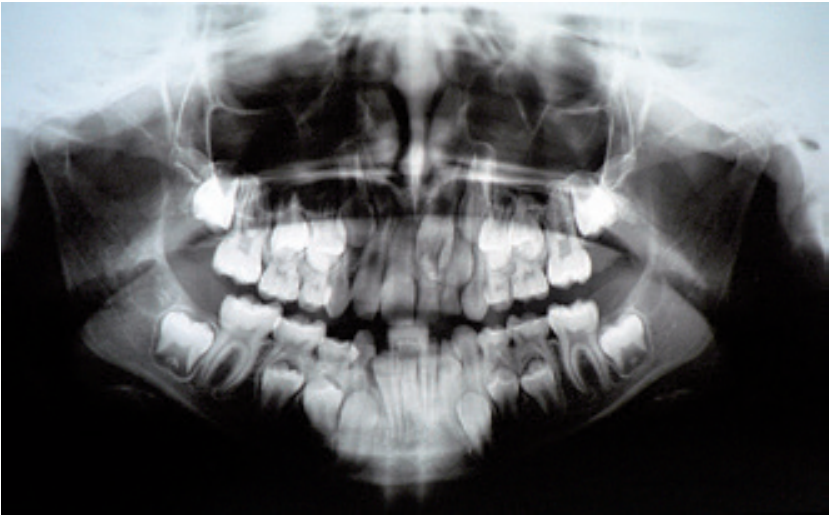

Fig. 1. A nine-year-old girl's panoramic x-ray: retained teeth 21 and 22 and supernumerary inclusion

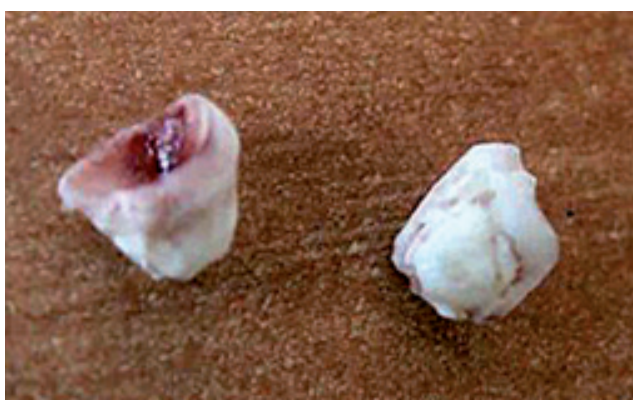

Fig. 2. The

same nineyear-old girl's super numerary teeth which were extracted

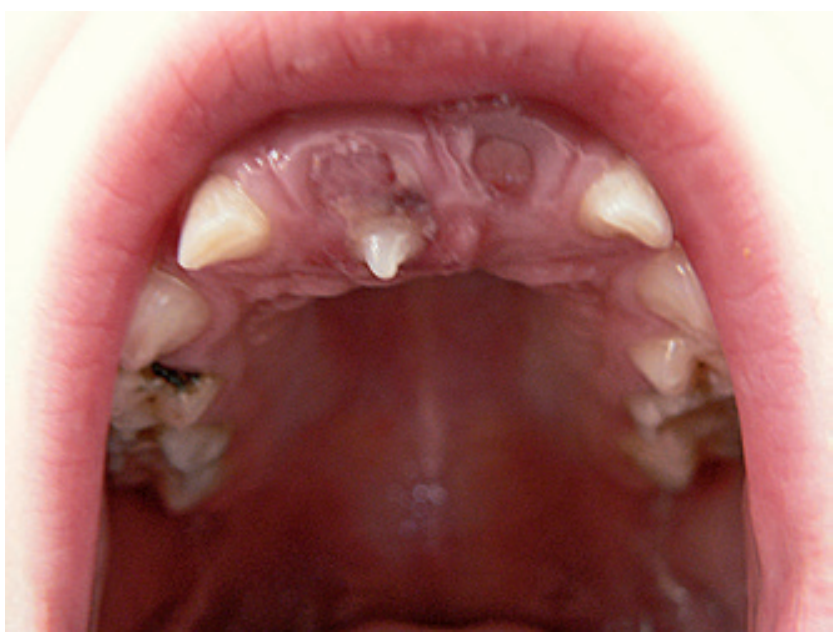

Fig. 3. A seven-year-old boy in the early period of primary occlusion; retention of teeth 11 and 21 caused by hyperdontia

mouth. The child's face was symmetrical and proportionate.

Clinical examination revealed the presence of a partially erupted conical tooth (Fig. 3). Radiological examination showed a supernumerary conical tooth between the central incisors that was preventing them from erupting. The left central incisor was rotated $45^{\circ}$ (Fig. 4).

After the supernumerary tooth was extracted (Fig. 5), the central incisors erupted independently within months,

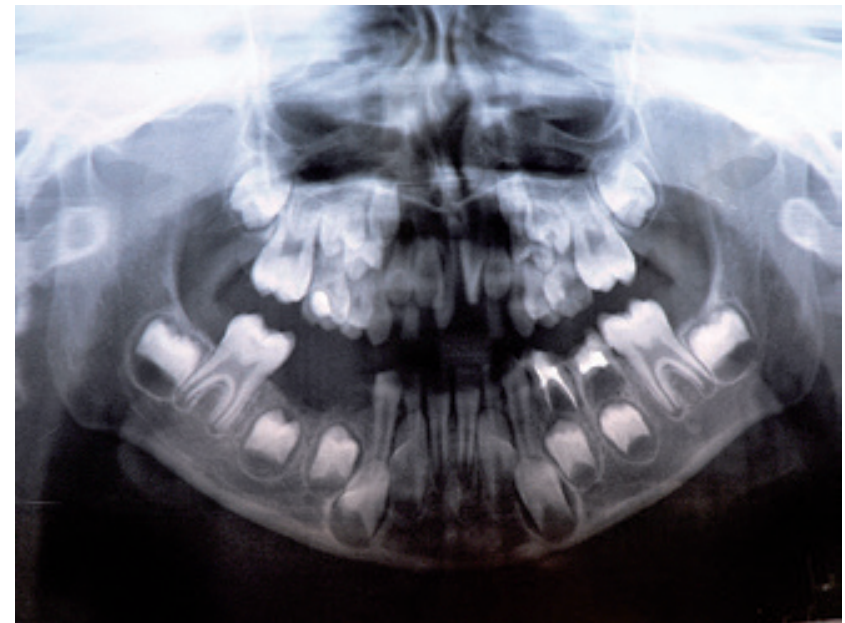

Fig. 4. The same seven-year-old boy's panoramic x-ray: a supernumerary tooth between central incisors, the left incisor in tortoanomalia

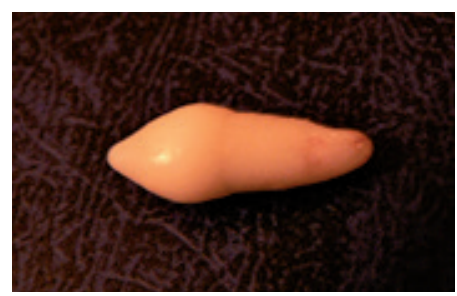

Fig. 5. Supernumerary teeth which were extracted from the seven-year-old boy

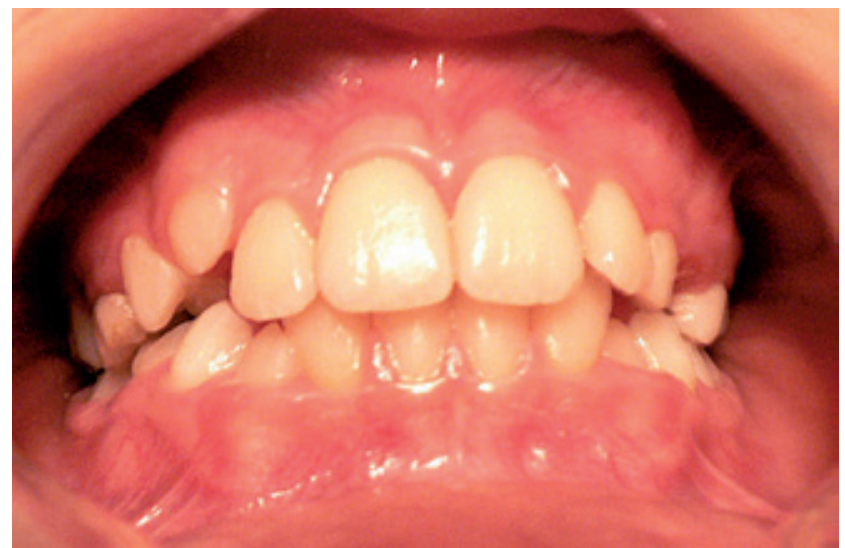

Fig. 6. The seven-year-old boy's central incisors erupted (photo seven months after treatment)

but were torsiverted. A removable appliance with an activation arm was used to correct the position of the central incisors. After five months positive functional and esthetic results were achieved (Fig. 6).

In patients with permanent occlusion, crown exposure of the retained tooth is performed simultaneously with the supernumerary tooth extraction, immediately followed by fixing the orthodontic element for its movement into the dental arch.

The objective of this intervention is to gain access to the crown of the retained tooth without damaging the mar- 
ginal edge of the gum. This provides a better esthetic effect in the area of the retained tooth that has been moved to the dental arch. In all cases, the central incisors were accessed from the vestibular side of the alveolar process.

If retention is caused by hyperdontia and after extraction of the supernumerary tooth/teeth the cavity in the jaw bone prevents the retained tooth from initiating movement, staged surgery might decided upon in some cases. The first stage is the exposure of the crown of the retained tooth. Once the supernumerary tooth shifts closer to the edge of the alveolar process as a result of the movement of the retained tooth, the second stage of the surgery is carried out: extraction of the supernumerary tooth, which is less invasive and traumatic for the bone and considerably shortens the post-surgical treatment time.

\section{Case 3}

A 22-year-old female came to the Depertment of Orthodontics complaining that an absent right upper canine caused an esthetic defect. Clinical examination revealed Angle's class 1 malocclusion, left-sided cross bite, teeth 33 and 34 in a vestibular position, and tooth 23 was missing. X-ray imaging (Fig. 7) showed the retained tooth 23 with a formed root and correct anatomical structure, and a supernumerary tooth causing the failure of tooth of 23 to erupt.

Non-removable Roth 0018 orthodontic appliance was fitted for the patient and after five months of treatment

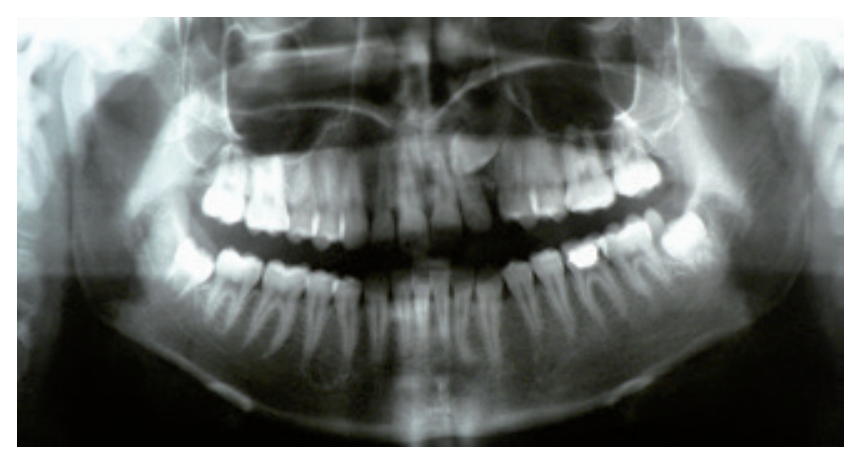

with open springs enough space was created to move tooth 23 into the dental arch.

An orthodontic button was fixed to the exposed surface of the retained 23 from the palatal side of the alveolar bone (Fig. 8). The double-arch method was used to move the retained tooth, using a $0.017 " \times 0.022$ " steel rectangular arch as the main stabilizing one and a 0.016 " round $\mathrm{NiTi}$ arch, which provides light continuous force on the retained tooth.

After 5 months of tooth 23 movement, when the supernumerary tooth started emerging and visualized on the vestibular surface of the alveolar bone, the second surgical procedure was performed: removal of the supernumerary tooth, after which the movement of the retained tooth continued. The total duration of the treatment was 23 months. After the treatment a removable retainer was made. In this case, the individual treatment plan and individualized approach allowed the retained tooth to be successfully moved without significant loss of volumetric bone density.

In some cases, when the supernumerary tooth is large in size or when a retained tooth cannot be accessed without extracting the supernumerary one, a large cavity is expected in the jaw bone. In this situation, orthodontic treatment is preceded by bone grafting. The following is a clinical example.

\section{Case 4}

A 21-year-old male came to the Department of Orthodontics complaining of the formation of a neoplasm on the upper left jaw. Clinical examination and x-ray (Fig. 9) led to a diagnosis of Angle's class 1 malocclusion, insignificant crowding of the teeth in the anterior area of the lower jaw, retention of tooth 23 , hyperdontia between teeth 22 and 23, and a follicular cyst.

In the Surgical Department under local anesthesia a trapezoid mucoperiosteal flap above the location of tooth 23 was mobilized. The follicular cyst was extracted and the crowns of the impacted 23 and the supernumerary tooth were exposed. To reduce the trauma from extraction, the

Fig. 7. A 22-year-old female's orthopantomogram

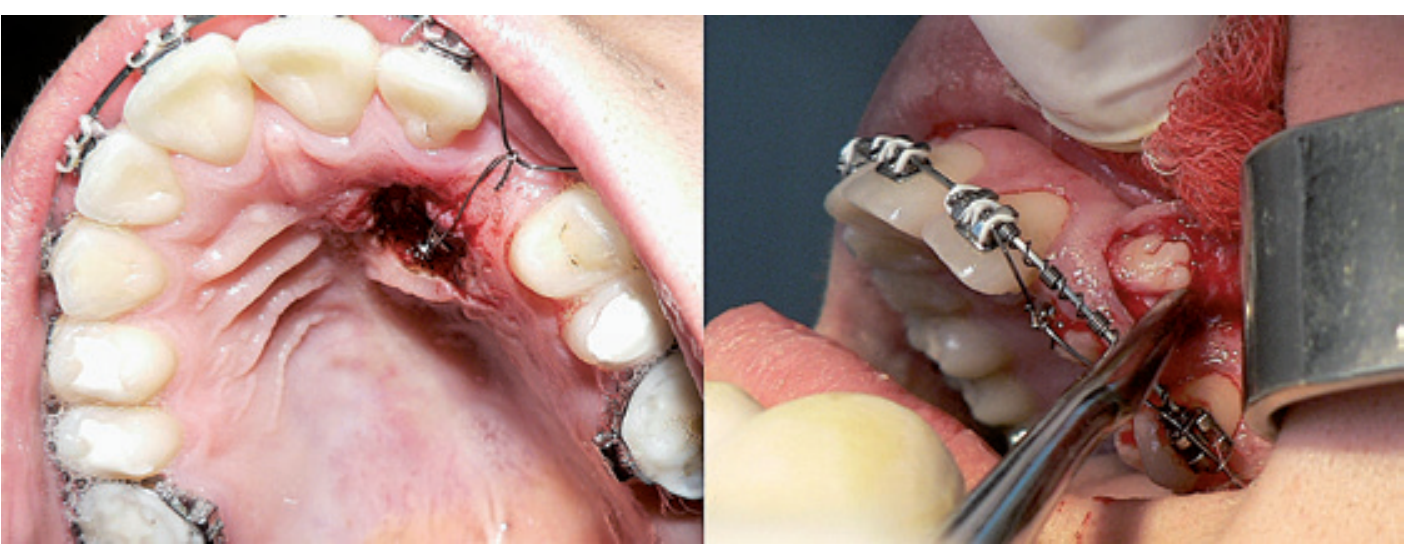

Fig. 8. The same 22-yearold female: surgical baring of the crown of tooth 23 and supernumerary tooth extraction 


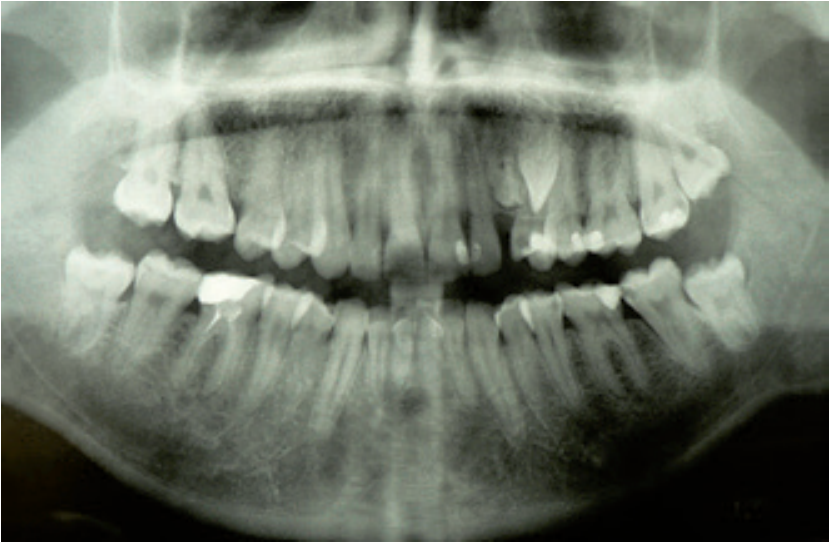

Fig. 9. A 21-year-old male's panoramic x-ray: impacted tooth 23 and hyperdontia

supernumerary tooth was divided beforehand into two parts with a bur and then extracted. Given the significant defect of the osseous tissue of the upper jaw in the location of the extracted cyst and supernumerary tooth, it was decided to place a bone graft. The cavity was filled with
1.5 g of Bio-Oss ${ }^{\circledR}$ (Geistlich Pharma, Wolhusen, Switzerland) and Bio-Gide ${ }^{\circledR}$ collagen membrane (Geistlich). The mucoperiostal flap was closed and the wound was sutured (Fig. 10). Postoperative instructions and the necessary prescriptions were given to the patient. The healing period passed without any complications.

After 6 months a second x-ray was taken, and it showed good osteointegration of the bone graft material (Fig. 11).

After 7 months the retained tooth erupted by itself, but in a vestibular position and turned around its axis. A nonremovable Roth 0018 orthodontic appliance with open springs was used to create sufficient space. The double arch method was used to move tooth 23 into the dental arch. Active treatment lasted for 7 months. The achieved result was satisfactory and stable (Fig. 12). After removing the braces the patient uses a removable retainer.

It is significant that in this situation the retained tooth erupted through the newly formed bone made of bone substitute. This way, full dentition was maintained, without extracting tooth 24 .
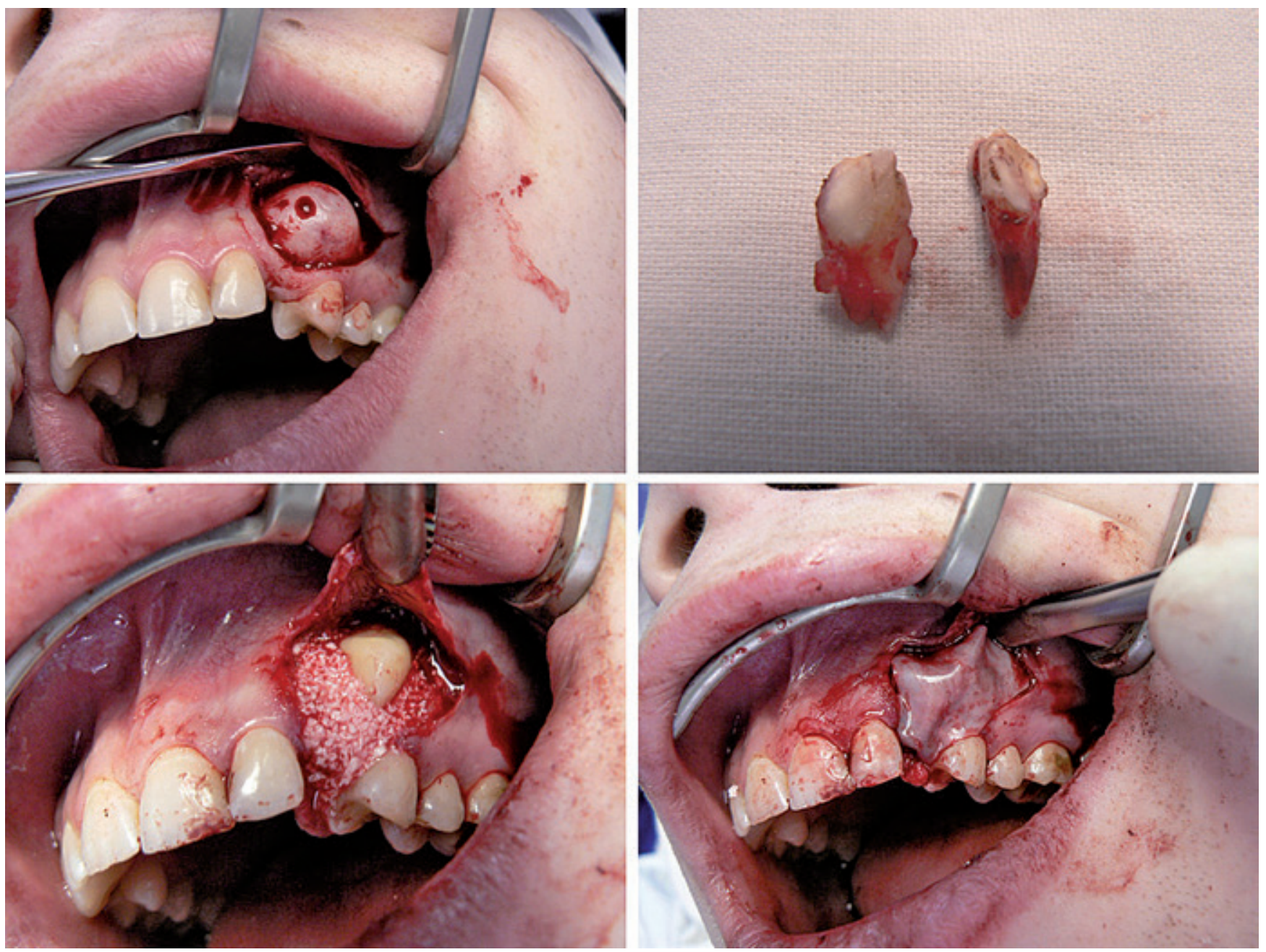

\footnotetext{
Fig. 10. The same 21-year-old male: the surgical stages of the treatment
} 


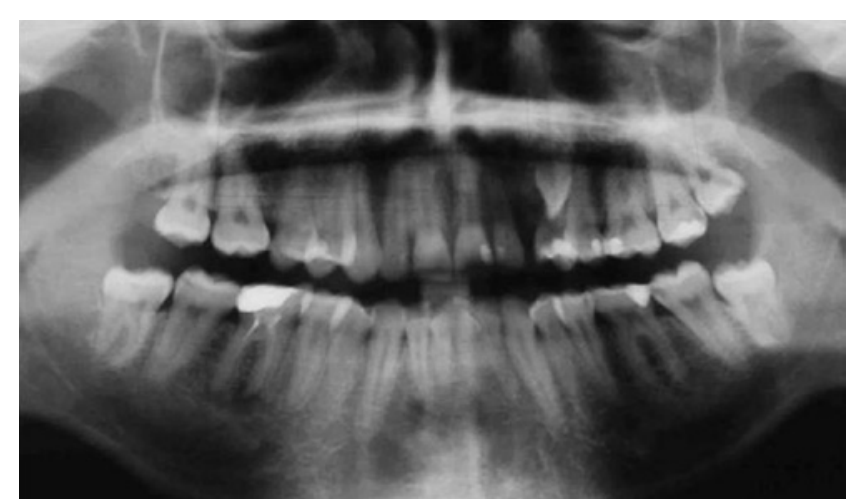

Fig. 11. The 21-year-old male's condition 6 months after osteoplasty; the demarcation line between his own bone and the bone substitute is not visible

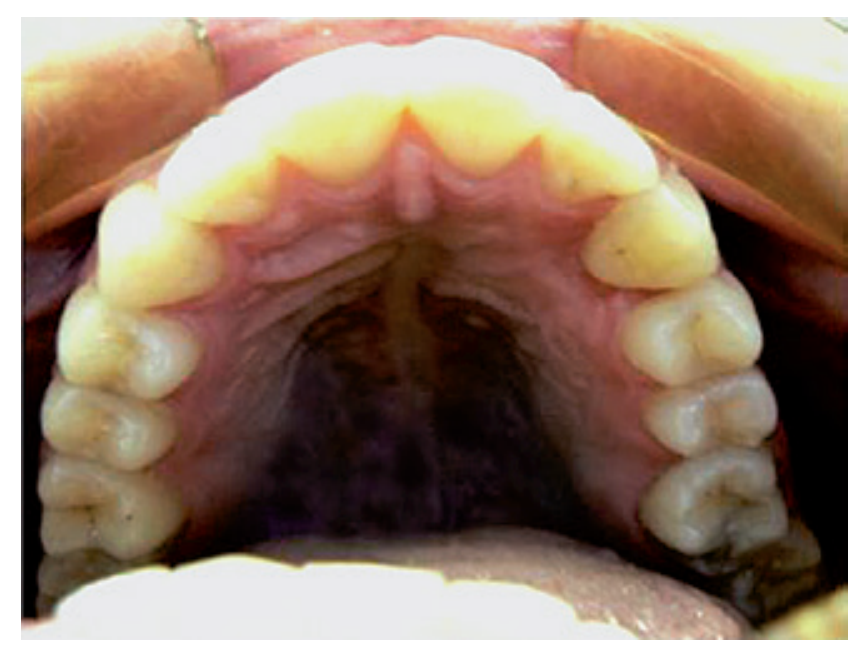

Fig. 12. The 21-year-old male's tooth 23 has moved into the dental row

\section{Discussion}

Retention of teeth in conjunction with hyperdontia is a complex condition that requires a carefully planned approach to the treatment. ${ }^{14}$ The choice of treatment should be individualized and based on a thorough examination. As Alling et al. wrote, "Methods of management of crowding or impaction due to supernumerary [teeth] are: remove supernumerary teeth or tooth only, remove supernumerary teeth and bone overlying impacted teeth, incision of fibrous tissue over the alveolar ridge to promote the eruption with or without orthodontic traction". ${ }^{15}$ To bring retained teeth into the dental arch, surgical exposure or surgical repositioning can be used in some cases. ${ }^{16,17}$

The authors' experience providing comprehensive care to patients with retained teeth due to supernumerary teeth led to the development of algorithms of orthodontic treatment for such cases (Fig. 13). The decision of which treatment plan to choose primarily depends on the physiological status of the functional dentition (primary or permanent), and the depth and location of the supernumerary tooth.

In a case of primary occlusion and both the retained tooth and the supernumerary tooth are located close to the surface, it is sufficient to extract the supernumerary tooth and wait for self-eruption of the retained tooth, if there is enough space in dental arch. In case of a delay in its eruption the use of a stimulating removable appliance is recommended.

In cases of patients with primary occlusion in which the location of the retained and supernumerary teeth is deep, it is appropriate to postpone treatment until the formation of permanent occlusion.

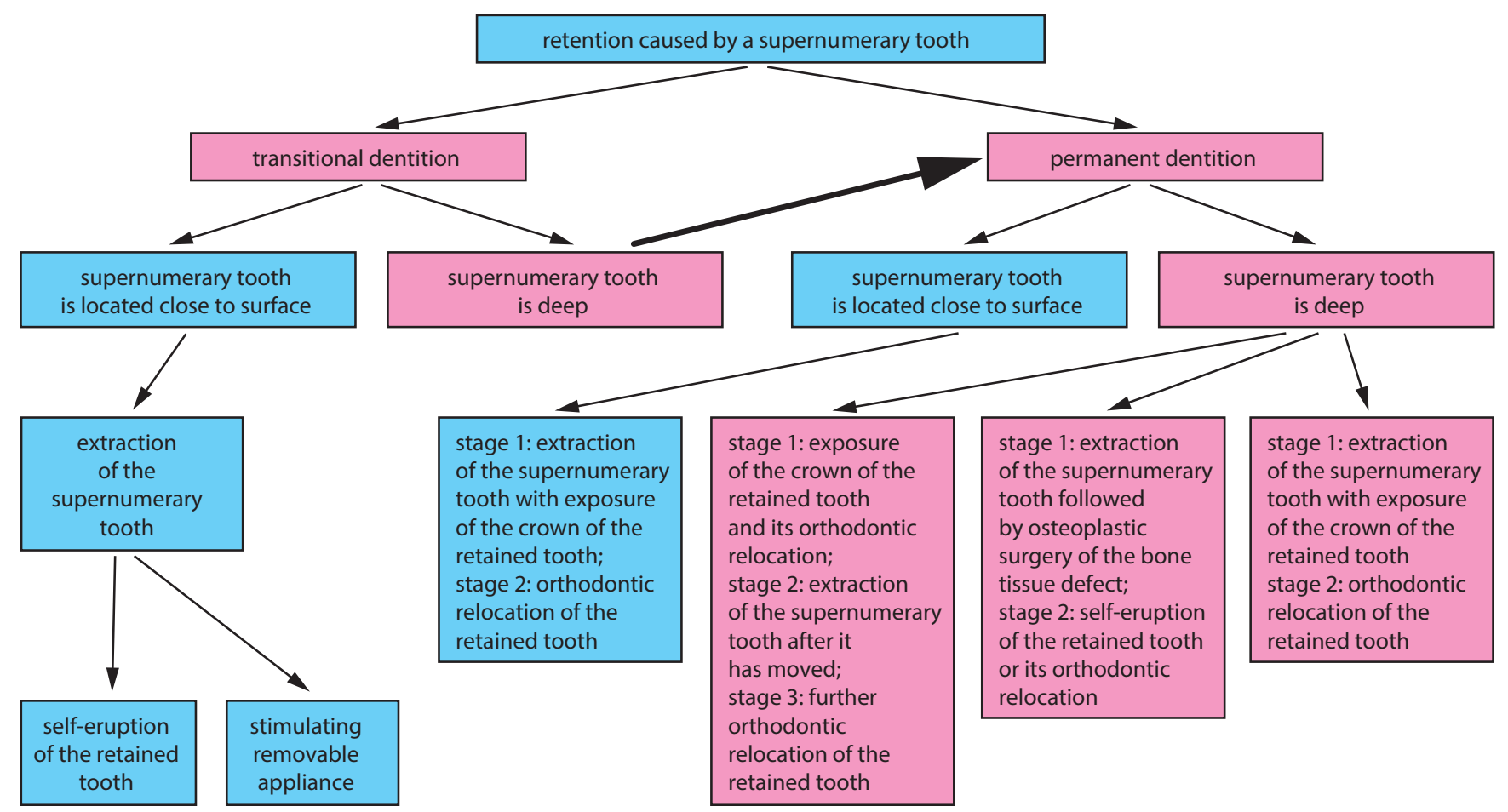

Fig. 13. The algorithm of action when retention caused by hyperdontia is discovered 
In cases of permanent occlusion when the retained and supernumerary teeth are located close to the surface, it is enough to extract the supernumerary tooth, expose the crown of the retained tooth and proceed with the orthodontic treatment scheme, which will depend on the availability of space in the dental arch. This treatment approach can be applied in some cases in which both teeth are deep but access to them and orthodontic relocation is not complicated.

However, in some clinical situations of a deep supernumerary tooth, it is advisable to carry out the exposure of the crown of the retained tooth and its orthodontic movement in the first stage. The movement of the retained tooth towards the crest of the alveolar bone will cause the relocation of the supernumerary tooth, which can be extracted in the second stage, under less traumatic conditions. Further orthodontic treatment is carried out in accordance with normal practice.

Sometimes there are clinical situations where as a result of removing a large supernumerary tooth, or several of them, and/or the removal of follicular cysts near the retained tooth, a large defect forms in the bone. In such cases, placing a bone graft with bone substitute and wound closure by mucoperiosteal flap is advisable. The retained tooth may erupt independently, or in the second stage (6-8 months later) it might be necessary to expose the crown of the retained tooth and move it with the help of orthodontic treatment.

With retained and supernumerary teeth, providing comprehensive care can be achieved by the algorithms described above, determined by the clinical situation: the topographical location of the retained and supernumerary teeth, size, their shape and number, the presence of follicular cysts, etc.

\section{References}

1. Rajab LD, Hamdan MAM. Supernumerary teeth: Review of the literature and a survey of 152 cases. Int J Paediatr Dent. 2002;12:244-254.

2. Bartolo A, Camilleri A, Camilleri S. Unerupted incisors - characteristic features and associated anomalies. Eur J Orthod. 2010;32:297-301.

3. Mitchell L, Bennett TG. Supernumerary teeth causing delayed eruption - a retrospective study. Br J Orthod. 1992;19:41-46.

4. Becker A, Casap N, Chaushu S. Conventional wisdom and the surgical exposure of impacted teeth. Orthod Craniofac Res. 2009;12:82-93.

5. Baart JA, Groenewegen BT, Verloop MA. Correlations between the presence of a mesiodens and position abnormalities, diastemas, and eruption disturbances of maxillary frontal teeth. Ned Tijdschr Tandheelkd. 2009;116:399-402.

6. Sant'Anna EF, Marquezan M, Sant'Anna CF. Impacted incisors associated with supernumerary teeth treated with a modified Haas appliance. Am J Orthod Dentofacial Orthop. 2012;142:863-871.

7. Becker A. Orthodontic treatment of impacted teeth. WileyBlackwell, 2012.

8. Mallineni SK. Radiographic localization of supernumerary teeth in the maxilla. Doctoral thesis. University of Hong Kong, 2011.

9. Anthonappa RP, King NM, Rabie ABM, Mallineni SK. Reliability of panoramic radiographs for identifying supernumerary teeth in children. Inter J Pediatr Dent. 2012;22:37-43.

10. Toureno L, Park JH, Cederberg RA, Hwang EH, Shin JW. Identification of supernumerary teeth in 2D and 3D: Review of literature and a proposal. J Dent Educat. 2013;77:43-50.

11. Jeremias F, Bullio Fragelli CM, Di Salvo Mastrantonio S, et al. Conebeam computed tomography as a surgical guide to impacted anterior teeth. Dent Res J. 2016;13:85-89.

12. Lai CS, Bornstein MM, Mock L, Heuberger BM, Dietrich T, Katsaros C. Impacted maxillary canines and root resorptions of neighboring teeth: A radiographic analysis using cone-beam computed tomography. Eur J Orthod. 2013;35:529-538.

13. Das D, Misra J. Surgical management of impacted incisors in associate with supernumerary teeth: A combine case report of spontaneous eruption and orthodontic extrusion. J Indian Soc Pedod Prev Dent. 2012;30:329-332.

14. Garvey MT, Barry HJ, Blake M. Supernumerary teeth - An overview of classification, diagnosis and management. J Can Dent Assoc. 1999;65:612-616.

15. Alling CA, Hellric JF, Alling R. Impacted teeth. WB. Saunders Co., Philadelphia, 1993, 46-49.

16. Kocadereli I, Turgut MD. Surgical and orthodontic treatment of an impacted permanent incisor: Case report. Dent Traumatol. 2005;21:234-239.

17. Kamakura S, Matsui K, Katou F, Shirai N, Kochi S, Motegi K. Surgical and orthodontic management of compound odontoma without removal of the impacted permanent tooth. Oral Surg Oral Med Oral Pathol Oral Radiol Endod. 2002;94:540-542. 